\title{
Determinants of HIV testing among young people aged $18-24$ years in South Africa
}

\author{
*Peltzer $\mathrm{K}^{1,2,3}$, Matseke $\mathrm{G}^{1}$
}

1. HIV/STI and TB (HAST) Research Programme, Human Sciences Research Council, Pretoria, South Africa.

2. Department of Psychology, University of Limpopo, Turfloop, South Africa.

3. ASEAN Institute for Health and Development, Mahidol University, Bangkok, Thailand

\begin{abstract}
Background: Although recent estimates of the HIV/AIDS burden in South Africa show the particular vulnerability of youth to HIV, HIV testing and its determinants are largely understudied in this age group.

Objective: To investigate the prevalence and determinants of HIV testing among young people aged 18 to 24 years, as part of an evaluation of the impact of loveLife.

Methods: South Africa's national HIV prevention campaign for young people, on HIV and related risk behaviours. A cross-sectional population-based household survey was conducted using a multistage stratified cluster sampling approach. The total sample included 3123 participants, aged 18-24, 54.6\% men and 45.4\% women, from four provinces (Eastern Cape, Gauteng, KwaZulu-Natal and Mpumalanga).

Results: The results indicated that over half $(52.2 \%)$ of the youth reported testing for HIV, with more young females (60.1\%) testing for HIV compared to their male counterparts (39.9\%). In the multivariate analysis, older age, being female, HIV knowledge, having ever talked to the mother or female guardian about HIV and having ever been pregnant or made someone pregnant were found to be associated with testing for HIV.

Conclusion: There is still room for improving the low proportion of young people who test for HIV. Specific attention needs to be paid to younger males, with lack of HIV knowledge, having never talked to the mother or female guardian about HIV and having never been pregnant or made someone pregnant were less likely to be tested. Outreach at individual and community levels and public health messages targeting these youth should be implemented.

African Health Sciences 2013; 13(4): 1012 - 1020 http://dx.doi.org/10.4314/ahs.v13i4.22
\end{abstract}

\section{Introduction}

HIV counselling and testing (HCT) is seen as a key strategy for reducing the spread of HIV infection in South Africa. ${ }^{1}$ HCT has become increasingly available in South Africa in recent years. More than 4500 public health facilities are offering providerinitiated testing and counselling (PICT) also known as routine HIV testing (RT) and client-initiated counselling and testing (CICT) also known as VCT. HCT is also offered through mobile services, as well as non-medical sites. ${ }^{2}$ HCT services should be enabled for the youth to take up HIV counselling and testing. ${ }^{2}$ In addition, the South African government launched a national HCT campaign in 2010, and reached almost 15 million South Africans to have tested for HIV by June $2011 .^{3}$

*Corresponding author:
Karl Peltzer
HIV/STI and TB (HAST) Research Programme
Human Sciences Research Council, Pretoria
South Africa
Email: kpeltzer@hsrc.ac.za

1012
However, although recent estimates of the HIV/AIDS burden in South Africa show the particular vulnerability of youth to HIV, HIV testing and its determinants are largely understudied in this age group. In the last national population-based survey in 2008 the HIV prevalence was estimated at $10.5 \%, 17.4 \%$ for women and $3.3 \%$ for men among young people aged $18-24$ years in South Africa. ${ }^{4}$ In previous national surveys among youth in South Africa it was found that in 2003 among sexually experienced youth (15-24 years old) $32.7 \%$ of females and $17.7 \%$ of males reported having been tested for HIV, in 2006 among youth (15-24 years) $30 \%$ reported ever been tested for HIV and $41 \%$ among those who ever had sexual intercourse, ${ }^{6}$ and in 2008 among youth (18-24 years) 47.8\% reported ever having tested for HIV, $31.4 \%$ among men and $64.1 \%$ among women, and among those who ever had sexual intercourse $56.3 \%$ had ever been tested for HIV, 36.3\% among men and $75.5 \%$ among women. ${ }^{4}$ Studies among youth (15-24 years) from other low and middle income countries found HIV testing rates ranging from $2.6 \%$ in Nigeria, ${ }^{7} 17 \%$ in Haiti, ${ }^{8} 28.9 \%$ in Tanzania, ${ }^{9} 36.8 \%$ in Guayana, ${ }^{8} 48 \%$

African Health Sciences Vol 13 Issue 4 December 2013 
in the Dominican Republic, ${ }^{9}$ to $64 \%$ among females and 55\% among males in Kisumu, Kenya. ${ }^{10}$

Factors associated with HIV testing among young people include demographic factors (age, sex, education, wealth), ${ }^{7,8}$ HIV risk behaviour, ${ }^{5,8,10}$ perceived HIV risk, ${ }^{11}$ psychosocial variables related to HIV knowledge, stigma attitudes, ${ }^{12,13}$ talked with parents about HIV/AIDS, ${ }^{5}$ pregnancy, ${ }^{5,11}$ and in general self-efficacy, ${ }^{14}$ frequent conversations about HIV,${ }^{15}$ health systems factors, ${ }^{16}$ programme exposure ${ }^{14}$ exposure to HIV media campaigns, exposure to HIV prevention programmes and general access to media. ${ }^{17}$

A few recent studies of HIV testing in Southern Africa could be located and none could be found which examined testing among youth 18"24 years. The purpose of this study, therefore, was to examine the prevalence and determinants of HIV testing among young people aged 18 to 24 years in South Africa. This research was conducted as part of an evaluation of the impact of loveLife, South Africa's national HIV prevention campaign for young people, on HIV and related risk behaviours. The largest youth HIV prevention programme in South Africa is loveLife; it was established in late 1999. It entails high powered media awareness and education, development of adolescent-friendly reproductive health services, and outreach and support activities. The brand includes youth centres, local mobilization led by groundBREAKERS and volunteer peer motivators known as 'mpintshis'. The programmes try to address simultaneously individual factors (e.g. low self-esteem), social factors (e.g. societal attitudes that disempower girls and young women; tolerance of violence in relationships) and structural factors (e.g. poverty, unemployment and school dropout) that are putting young people at risk of infection. ${ }^{18}$

\section{Method}

\section{Sample and procedures}

A cross-sectional population-based household survey was conducted using a multi-stage stratified cluster sampling approach. A total of 583 census enumeration areas (EAs) from the 2001 population census were selected from a database of 86000 EAs and mapped in 2007 using aerial photography to create a new updated master sample to use as a basis for sampling households. The selection of EAs was stratified by province and locality type. Locality types were urban formal, urban informal, rural formal (including commercial farms), and rural informal. In the formal urban areas, race type was also used as a third stratification variable (based on the predominant racial group in the selected EA at the time of the 2001 census).

The allocation of EAs to different stratification categories was disproportionate, that means, over-sampling or over-allocation of EAs occurred in areas that were dominated by Indian, Coloureds or White population groups to ensure that the minimum required sample size in those smaller racial groups is obtained. The selected 583 EAs informed the primary sampling units (PSUs). A visiting point was defined as a stand with an address that might have one or more than one household. A household was defined as a group of people living and eating together from the same pot. ${ }^{19}$ Visiting points (VPs) or households were used as secondary sampling units (SSUs). Within each household, all eligible individuals (including consenting and nonconsenting individuals) aged 18 to 24 years selected for the survey were the ultimate sampling unit (USU). To obtain an approximately self-weighted sample of visiting points (i.e. SSUs), the EAs were sampled with probability proportional to the size of the EA using the 2001 census estimate of the number of visiting points in the EA database as a measure of size (MOS). Subsequently, an equal number of VPs (12) were systematically drawn from each selected EA.

In each household all eligible household members were invited to participate and interviewed. The survey included persons of ages 18 to 24 years living in South African households of the four (out of nine) selected provinces, KwaZuluNatal, Mpumalanga, Eastern Cape and Gauteng Province, providing an urban-rural representation of South Africa. The selection of the provinces was guided by selecting two provinces with the highest HIV prevalence in the country, KwaZulu-Natal and Mpumalanga, and one most urban province (Gauteng) and one rural province (Eastern Cape).

In urban areas, fieldwork activities were conducted mostly during early evenings and over weekends, while in rural areas the timing of fieldwork activities varied depending on seasonal farming activities in the area and the times when people were most readily available. Field work was conducted from May to September 2011.

Ethical approval for the study was obtained from the HSRC Research Ethics Committee. Participants 
signed informed consent forms before taking part in the study.

\section{Measures}

Sociodemographic factors assessed included age, sex, formal education, marital status, highest educational qualification, and predominant living arrangements.

HIV testing history was assessed by asking participants about their frequency of HIV testing, and if never, whether they wanted to know their HIV status or not, how long ago they had their most recent test, and what their HIV status was. The indicators for sexual risk behaviour were: ever used a condom, whether they used a condom in the last sex with their most recent regular, non-regular and transactional sexual partners, and how often (consistency) they used a condom with each of these partners; the number of regular and non-regular sexual partners in their lifetime and in the past 12 months, and diagnosed with a sexually transmitted infection (STI) in their lifetime and in the past 12 months. Coercion was assessed with 1 item "Have you ever had sex because someone used physical force to make you have sex with him or her?" Parental communication was assessed with 2 items: "Who have ever you talked to about HIV/AIDS issues" 1) Mother or female primary care giver/ guardian and 2) Father or male primary care giver/ guardian. HIV knowledge was assessed with two items: 1) How many people living with HIV do you personally know? And 2) How many people have you personally known (in your lifetime) that have died from AIDS? Responses of the two questions were added up and coded as $0=$ does not know anyone both living with HIV and has died of HIV/ AIDS, $1=$ knows any person living with HIV (PLHIV) or who has died from AIDS, and $2=$ knows any PLHIV and a person who has died from AIDS. Partner risk reduction self-efficacy was assessed with 4 items such as "Would you be able to avoid sex any time you didn't want it?" Response options were: No, Probably no, Probably yes, Yes. Cronbach alpha for this partner risk reduction self-efficacy index was 0.73 in this sample. HIV/AIDS stigma was assessed with four items, e.g., "If you knew a shopkeeper or food seller had HIV, would you buy food from them?" Response options were "yes" or "no". Cronbach alpha for this HIV/AIDS stigma index was 0.58 . Responses were summed up, and if any of the 4 questions were affirmative for stigma it was coded $=1$, against $=0$.
LoveLife HIV youth prevention programme exposure was assessed with the following items. Exposure to ever loveLife face to face programmes was assessed with 24 items, e.g., Gone to a loveLife clinic, Participated in a loveLife Community Dialogue, or Gone to a loveLife Youth Centre. LoveLife exposure to face-to-face programmes was summed up and coded as $0,1-2,3-4$ or 5 or more programme exposures. In addition, loveLife multimedia exposure was assessed with 9 items, e.g., "Have you ever watched a loveLife television show?" "Contacted loveLife on Facebook" "Heard a loveLife advert on radio." "Read UNCUT (loveLife) youth magazine." Response options were $1=$ Yes or $2=$ No. The 9 multi-media programmes were summed up and coded as 1=0-1 media exposures, $2=2-4$, and $3=5-9$ media exposures.

\section{Data management and analysis}

The data were entered using Census Survey Processing software (CSPro). Data from the questionnaires were entered manually and verified. The verification process included double data entry of all questionnaires and its fields, doing programmed range checks by computer to identify outlying values, checking for missing values, and checking for inconsistencies in the data. Due to the sampling design of the survey some individuals have a greater or lesser probability of selection than others. To correct this problem, sample weights were introduced to correct for potential bias at the EA, household and individual levels and also adjust for non-response. Weighting procedures were undertaken before analysis of the data as follows: the data file of drawn EAs and sites contained the selection probabilities as well as the sampling weights of these EAs and sites. These weights reflect the disproportionate allocation of EAs and sites according to the stratification variables - race, locality type and province. The VP sampling weight was then calculated. This weight was computed as the counted number of VPs in the EA/site, proportionally corrected for invalid VPs and divided by the number of VPs participating in the survey. The final VP sampling weight was the product of the EA/site sampling weight and the VP sampling weight since all eligible persons in the household were invited to participate.

Analysis was done using STATA software package taking into account the complex multi-level 
sampling design. Weighted percentages are reported in the analysis and sample sizes refer to the actual number of individuals who responded to the selected questions. Descriptive analysis was conducted to explore characteristics of the sample while bivariate and logistic regression analyses were conducted to establish factors associated with HIV testing. Some of the independent variables were identified from the literature as possible factors that may be associated with HIV testing behaviour. Unadjusted odds ratios were reported for while considering 'ever testing for HIV' as a dependent variable. We therefore report the results of adjusted odds ratios for the factors, having controlled for factors as significant $(\mathrm{P}<.05)$ in the bivariate analysis. The two-sided $95 \%$ confidence intervals are reported. The p-value less or equal to $5 \%$ is used to indicate statistical significance in all the analyses.

\section{Results}

\section{Sample characteristics}

The total sample included 3127 participants, aged $18-24,54.6 \%$ men and $45.4 \%$ women. The mean age of the sample was 20.5 years $(S D=2.1)$. Only
$1.7 \%(n=59)$ of the youth reported being married. Half of the participants $(50.8 \%)$ were students, and $61.9 \%$ had an educational level of grade 12 or more. More than one-thirds of the youth $(36.8 \%)$ knew a PLHIV and a person who died from AIDS. With regard to HIV risk behaviour, $6.1 \%$ reported having been diagnosed with a sexually transmitted infection (STI) in their lifetime, $22.6 \%$ had two or more sexual partners in the past 12 months, 35\% reported inconsistent condom use and $62.5 \%$ no condom use with a transactional sex partner. Regarding social factors, $65.2 \%$ indicated that they had ever talked to their mother of female guardian about HIV, 59.4\% had partner HIV risk reduction self-efficacy, and 5.1\% AIDS stigmatizing attitudes. Among women 42.7\% indicated that they had ever been pregnant and among men $22.1 \%$ reported that they had ever made someone pregnant. From all participants 52.2\% indicated that they have had an HIV test, 39.9\% among men and $60.1 \%$ among women. Among participants who indicated that they ever had sex the HIV testing uptake was $63.6 \%, 47.7 \%$ among men and $80.5 \%$ among women (see table 1).

Table 1: Sample characteristics by HIV testing status

\begin{tabular}{lccc}
\hline & $\begin{array}{l}\text { Never tested } \\
\mathbf{N}(\%) \text { or } \\
\text { (SD) }\end{array}$ & $\begin{array}{c}\text { Ever tested } \\
\mathbf{N}(\%) \text { or M } \\
\text { (SD) }\end{array}$ & $\begin{array}{c}\text { Total } \\
\text { N (\%) or M } \\
\text { (SD) }\end{array}$ \\
\hline All & $1395(47.8)$ & $1589(52.2)$ & 3123 \\
Gender & & & \\
Male & $925(60.1)$ & $664(39.9)$ & $1619(54.6)$ \\
Female & $466(39.9)$ & $924(60.1)$ & $1417(45.4)$ \\
Mean age in years (standard deviation) & $20.0(2.0)$ & $21.0(2.1)$ & $20.5(2.1)$ \\
Employment status & & & \\
Student & $746(56.7)$ & $641(43.3)$ & $1389(50.8)$ \\
Employed & $140(27.2)$ & $231(72.8)$ & $372(12.9)$ \\
Unemployed & $391(41.0)$ & $600(59.0)$ & $993(36.3)$ \\
Educational level & & & \\
Grade 10 or less & $283(48.9)$ & $284(51.1)$ & $570(17.6)$ \\
Grade 11 & $260(55.1)$ & $322(44.9)$ & $685(20.9)$ \\
Grade 12 or more & $747(45.1)$ & $975(54.9)$ & $1728(61.9)$ \\
HIV knowledge & & & \\
Knows person living with HIV and/or died from AIDS & & & $1109(43.9)$ \\
0 & $674(57.5)$ & $435(42.5)$ & $634(19.3)$ \\
1=knows PLHIV or died from AIDS & $293(54.4)$ & $341(45.6)$ & $1221(36.8)$ \\
2=knows PLHIV and died from AIDS & $421(33.1)$ & $800(66.9)$ & \\
HIV risk behaviour & & & $241(6.1)$ \\
Had STIs in lifetime & $63(28.9)$ & $178(71.1)$ & $727(22.6)$ \\
Two or more sexual partners in past year & $335(45.3)$ & $392(54.7)$ & $305(34.6)$ \\
Inconsistent condom use & $114(39.5)$ & $191(60.5)$ & $240(62.5)$ \\
No condom use with transactional sex partner & $83(47.7)$ & $157(52.3)$ &
\end{tabular}




\begin{tabular}{llcc}
\hline Never tested & $\begin{array}{l}\text { Ever tested } \\
\mathbf{N}(\%) \text { or } \mathbf{M}\end{array}$ & $\begin{array}{l}\text { Total } \\
\mathbf{N}(\mathbf{\%}) \text { or } \mathbf{M} \\
\text { (SD) }\end{array}$ & $\begin{array}{c}\text { N (\%) or M } \\
\text { (SD) }\end{array}$ \\
\hline Sex with much older person & $70(19.0)$ & $233(81.0)$ & $303(11.3)$ \\
Ever forced to have sex & $14(19.7)$ & $58(80.3)$ & $72(4.1)$ \\
Social factors & & & \\
Ever talked to mother/female guardian about HIV & $813(42.2)$ & $1154(57.8)$ & $1970(65.2)$ \\
Ever talked to father/male guardian about HIV & $400(44.8)$ & $546(55.2)$ & $949(33.8)$ \\
Partner HIV risk reduction self efficacy & $745(45.8)$ & $789(54.2)$ & $1534(59.4)$ \\
AIDS stigma & $258(55.4)$ & $122(44.6)$ & $258(5.1)$ \\
Ever been pregnant -female & $40(6.6)$ & $439(93.4)$ & $479(42.7)$ \\
Ever made someone pregnant-male & $77(23.7)$ & $166(76.3)$ & $243(22.1)$ \\
loveLife HIV prevention programme exposure & & & \\
loveLife face-to-face participation & & & \\
0 & $961(48.9)$ & $983(51.1)$ & $2085(67.7)$ \\
1-2 & $233(44.6)$ & $303(55.4)$ & $537(16.7)$ \\
3-4 & $101(45.5)$ & $129(54.5)$ & $230(6.7)$ \\
5 or more & $94(48.7)$ & $160(51.3)$ & $255(8.5)$ \\
loveLife multi-media exposure & & & \\
0-1 & $325(56.6)$ & $264(43.4)$ & $592(22.8)$ \\
2-4 & $669(46.6)$ & $757(53.4)$ & $1427(48.4)$ \\
5-9 & $364(42.7)$ & $513(57.3)$ & $878(28.8)$ \\
\hline
\end{tabular}

HIV testing characteristics

From all participants, $25.8 \%$ indicated that they had been tested once for HIV and $26.4 \%$ more than once. For most participants their recent HIV test was less than a year ago $(73.9 \%)$. There were similar ever HIV testing rates among men and women, while women significantly more than men tested for HIV more than once. Among those participants who had not tested for HIV, half $(50.4 \%)$ indicated that they would want to know their HIV status. This readiness for an HIV test was significantly higher among women than men (see table 2).

\section{Determinants of ever HIV testing}

In multivariable analysis, older age, being female, HIV knowledge, having ever talked to the mother or female guardian about HIV and having ever been pregnant or made someone pregnant were found to be associated with HIV testing (see table 3).

\section{Table 2: HIV testing characteristics}

\begin{tabular}{lllll}
\hline & All & Male & Female & P-value \\
\hline Number of times tested for HIV & & & & \\
Never & $1395(47.8)$ & $925(61.9)$ & $466(30.9)$ & 0.000 \\
Once & $821(25.8)$ & $410(24.6)$ & $410(27.1)$ & \\
More than once & $768(26.4)$ & $254(13.5)$ & $510(42.1)$ & \\
Time of most recent HIV test & & & & \\
Less than a year ago & $1132(73.9)$ & $474(71.7)$ & $657(75.3)$ & Non-significant \\
Between 1-2 years & $351(18.7)$ & $155(19.8)$ & $196(18.2)$ & \\
Between 2-3 years & $101(4.9)$ & $41(5.3)$ & $60(4.7)$ & \\
Three or more years ago & $52(2.4)$ & $23(3.3)$ & $29(1.8)$ & \\
Do you want to know your HIV status & & & \\
Yes & $465(50.4)$ & $320(45.6)$ & $144(63.2)$ & 0.000 \\
No & $217(27.0)$ & $168(26.8)$ & $48(27.4)$ & \\
Unsure & $89(22.6)$ & $63(27.5)$ & $25(9.4)$ & \\
\hline
\end{tabular}


Table 3: Determinants of HIV testing

\begin{tabular}{|c|c|c|c|c|}
\hline & $\begin{array}{l}\text { Unadjusted } \\
\text { Odds ratio } \\
(95 \% \mathrm{CI})\end{array}$ & p-value & $\begin{array}{l}\text { Adjusted } \\
\text { Odds ratio } \\
(95 \% \mathrm{CI}) \\
\end{array}$ & p-value \\
\hline \multicolumn{5}{|l|}{ Demographics } \\
\hline Age & $1.25(1.14-1.37)$ & 0.000 & $1.001(1.00-1.001)$ & 0.046 \\
\hline \multicolumn{5}{|l|}{ Gender } \\
\hline Female & 1.00 & & 1.00 & \\
\hline Male & $0.27(0.20-0.39)$ & 0.000 & $0.25(0.12-0.54)$ & 0.000 \\
\hline \multicolumn{5}{|l|}{ Employment status } \\
\hline Student & 1.00 & & 1.00 & \\
\hline Employed & $3.50(1.61-7.57)$ & 0.002 & $2.35(0.53-10.48)$ & 0.261 \\
\hline Unemployed & $1.88(1.43-2.47)$ & 0.000 & $1.13(0.69-1.85)$ & 0.627 \\
\hline \multicolumn{5}{|l|}{ Educational level } \\
\hline Grade 10 or less & 1.00 & & -- & \\
\hline Grade 11 & $0.78(0.48-1.28)$ & 0.322 & & \\
\hline Grade 12 or more & $1.16(0.77-1.75)$ & 0.466 & & \\
\hline \multicolumn{5}{|l|}{ HIV knowledge } \\
\hline \multicolumn{5}{|c|}{ Knows person living with HIV and/or died from AIDS } \\
\hline 0 & 1.00 & & 1.00 & \\
\hline $1=$ knows PLHIV or died from AIDS & $1.14(0.56-2.29)$ & 0.072 & $0.64(0.31-1.31)$ & 0.219 \\
\hline $2=$ knows PLHIV and died from AIDS & $2.74(1.68-4.49)$ & 0.000 & $1.79(1.05-3.06)$ & 0.032 \\
\hline \multicolumn{5}{|c|}{ HIV risk behaviour } \\
\hline Ever forced sex & $2.41(0.74-7.85)$ & 0.145 & -- & \\
\hline Had STIs in lifetime & $2.36(1.40-3.99)$ & 0.001 & $1.55(0.65-3.68)$ & 0.319 \\
\hline $\begin{array}{l}\text { Two or more sexual partners in past } \\
12 \text { months }\end{array}$ & $1.14(0.79-1.63)$ & 0.479 & - & \\
\hline $\begin{array}{l}\text { Inconsistent condom use with most } \\
\text { recent non-regular partner }\end{array}$ & $1.04(0.62-1.75)$ & 0.873 & -- & \\
\hline $\begin{array}{l}\text { No condom use with transactional sex } \\
\text { partner }\end{array}$ & $0.43(0.13-1.39)$ & 0.158 & -- & \\
\hline Sex with someone much older & $2.68(1.61-4.49)$ & 0.000 & $1.23(0.62-2.44)$ & 0.549 \\
\hline \multicolumn{5}{|l|}{ Social factors } \\
\hline $\begin{array}{l}\text { Ever talked to mother/female guardian } \\
\text { about HIV }\end{array}$ & $1.88(1.42-2.49)$ & 0.000 & $2.69(1.61-4.55)$ & 0.000 \\
\hline $\begin{array}{l}\text { Ever talked to father/male guardian } \\
\text { about HIV }\end{array}$ & $1.20(0.81-1.77)$ & 0.366 & -- & \\
\hline Partner HIV risk reduction self-efficacy & $1.05(0.95-1.16)$ & 0.356 & -- & \\
\hline AIDS Stigma & $0.73(0.38-1.42)$ & 0.358 & -- & \\
\hline $\begin{array}{l}\text { Ever pregnant or made someone } \\
\text { pregnant }\end{array}$ & $5.94(3.82-9.21)$ & 0.000 & $5.71(3.27-9.97)$ & 0.000 \\
\hline \multicolumn{5}{|c|}{ loveLife HIV prevention programme exposure } \\
\hline \multicolumn{5}{|c|}{ loveLife face-to-face participation } \\
\hline 0 & 1.00 & & & \\
\hline $1-2$ & $1.19(0.76-1.85)$ & 0.447 & & \\
\hline $3-4$ & $1.15(0.64-2.05)$ & 0.645 & & \\
\hline 5 or more & $1.01(0.39-2.61)$ & 0.990 & -- & \\
\hline \multicolumn{5}{|l|}{ loveLife multi-media exposure } \\
\hline $0-1$ & 1.00 & & 1.00 & \\
\hline $2-4$ & $1.47(0.96-2.25)$ & 0.078 & $1.67(0.79-3.54)$ & 0.180 \\
\hline $5-9$ & $1.84(1.10-3.10)$ & 0.021 & $2.07(0.97-4.43)$ & 0.061 \\
\hline
\end{tabular}




\section{Discussion}

The study found that from all participants (18-24 years) $52.2 \%$ indicated that they have had an HIV test $(39.9 \%$ among men and $60.1 \%$ among women) in 2011 in South Africa. Among sexually experienced participants the HIV testing uptake was $63.6 \%$ (47.7\% among men and $80.5 \%$ among women). This finding seems to show a similar HIV testing uptake compared to 2008 among youth (18-24 years) $47.8 \%$ reported ever having tested for HIV, $31.4 \%$ among men and $64.1 \%$ among women, and among those who ever had sexual intercourse $56.3 \%$ had ever been tested for HIV, 36.3\% among men and 75.5\% among women. ${ }^{4}$ The reported HIV testing uptake in this study still remains low at $52.2 \%$ despite the increase in campaigns promoting HIV testing and increased availability of HCT services in South Africa.

In agreement with other studies, 5,7,8,11,12,15 this study found that older age, being female, HIV knowledge, having ever talked to the mother or female guardian about HIV and having ever been pregnant or made someone pregnant were found to be associated with HIV testing. This age disparity may be due to the likelihood that younger youths have had a shorter sexual experience and are less informed on sexual issues than older youth. ${ }^{7}$ The fact that more women than men in this study have reported a higher HIV testing uptake is not surprising since men and women have different health care seeking behaviours. In most situations, women are more likely to seek medical help and visit health care facilities than men. This was substantiated by other studies that have shown that women were far more likely to utilize HIV testing services or test for HIV compared to men. ${ }^{20-22}$ Having been pregnant or making someone pregnant was found to be the highest predictor for HIV testing uptake. Pregnant women presenting to the clinic for antenatal care are exposed to provider initiated HIV counselling and testing and who understand the potential of HIV testing for reducing mother-to-child transmission (PMTCT) are more likely to undergo HIV testing. Similarly, male partners who made someone pregnant seemed through the context of PMTCT undergo more likely HIV testing. Targeting pregnant youth for HIV testing is important for PMTCT and provides a potentially important avenue to reach partners of pregnant youth. ${ }^{11}$ Further, youth who knew any PLHIV and a person who has died from AIDS were more likely to have tested for HIV. If youth are impacted by personal knowledge of an AIDS death, to the point that they change their behaviours, we must continue to encourage discourse about HIV/AIDS with the hope that persons dying from AIDS will feel more comfortable disclosing their diagnosis to the youth they know and others. ${ }^{23}$ Among the youth HIV testing was associated with reporting ever talking to the mother or female guardian about HIV. While all communication about HIV may be beneficial, the role of parental communication in reducing HIV risk among youth has been documented previously. ${ }^{5,12}$ This supports the continued need to engage the mother or female guardian in discussions about HIV and sexuality with their children. ${ }^{4}$ These factors identified to be associated with an HIV test should be used to inform current HIV testing uptake programmes. One of the keys to HIV testing coverage among young people is also the availability of youth-friendly HIV testing services.

Unlike other studies, ${ }^{5,8,10,12-14,17}$ HIV risk behaviour, stigma attitudes, self-efficacy, and HIV prevention programme exposure were not found to be associated with HIV testing uptake. A concern is that high HIV risk behaviour (multiple sexual partners and inconsistent condom use) did not lead no higher rates of HIV testing meaning that these youth, in particular men, are exposing themselves to higher risks for HIV and will more likely ignorantly infect their numerous partners which will further worsen the HIV prevalence in South Africa, especially within this age.

\section{Study limitations}

Although the sample included in the study is not a national probability sample, it does include a representative sample of youth (aged 18-24 years) from four of the nine provinces in South Africa. As this survey is cross-sectional no causal conclusions can be drawn. In addition, the self-report of the variables assessed in the survey may be influenced by social desirability bias. Several variables affecting HCT uptake were not assessed in this study such as experience of counselling, influence of partners, fear of discrimination, ${ }^{7}$ perceived vulnerability and risk, ${ }^{11}$ underlying reasons for the uptake or lack thereof of HIV testing, ${ }^{24}$ marital aspirations, ${ }^{10}$ urban-rural locality, ${ }^{5,8,10}$ type HCT utilization, and negative beliefs about the health care system ${ }^{25}$ and should be included in future studies. 


\section{Conclusion}

HIV testing among South African youth is low. Younger males, with lack of HIV knowledge, having never talked to the mother or female guardian about HIV and having never been pregnant or made someone pregnant were less likely to be tested. Outreach at individual and community levels and public health messages targeting these youth should be implemented. There is also a need to mainstream gender into the design of programmes aimed at increasing uptake of HIV testing. Programmes which assist youth in accurately assessing their risk behaviours are also required to improve HIV testing.

\section{Acknowledgement}

This research was a collaborative project between loveLife and the Human Sciences Research Council, and was made possible by the Henry J. Kaiser Family Foundation. We would like to acknowledge loveLife and the anonymous review committee for their comments and suggestions. We would also like to thank the research participants who took part in the study.

\section{References}

1. National Department of Health. National Strategic Plan on HIV \& AIDS and STIs: 20072011. Pretoria: National Department of Health, 2007.

2. Department of Health. National HIV counselling and testing (HCT) policy guidelines. Pretoria: Department of Health, 2010.

3. SAinfo. South Africans, know your HIV status! Retrieved from http://www.southafrica.info/ playyourpart/hiv-testing.htm, 2011; accessed 15 February 2012.

4. Shisana O, Rehle T, Simbayi LC, et al. South African national HIV prevalence, incidence, behaviour and communication survey 2008: A turning tide among teenagers? Cape Town: HSRC Press; 2009.

5. MacPhail C, Pettifor A, Moyo R, Rees H. Factors associated with HIV testing among sexually active South African youth 15-24 years. AIDS Care 2009, 21: 456-67.

6. The Henry J. Kaiser Family Foundation and South African Broadcasting Corporation. Young South Africans, broadcast media, and HIV/ AIDS Awareness: Results of a national survey, 2007. Retrieved at http://www.kff.org/ southafrica/upload/7614.pdf, accessed 15 Febr 2012.
7. Nwachukwu CE, Odimegwu C. Regional patterns and correlates of HIV voluntary counselling and testing among youths in Nigeria. Afr J Reprod Health 2011; 15(2):131-46.

8. Andrews B. Sociodemographic and behavioural characteristics of youth reporting HIV testing in three Caribbean countries. West Indian Med J. 2011; 60(3):276-83.

9. Lema LA, Katapa RS, Musa AS. Knowledge on HIV/AIDS and sexual behaviour among youths in Kibaha District, Tanzania. Tanzan J Health Res. 2008;10(2):79-83.

10. Kabiru CW, Luke N, Izugbara CO, Zulu EM. The correlates of HIV testing and impacts on sexual behavior: evidence from a life history study of young people in Kisumu, Kenya. BMC Public Health 2010;10:412.

11. Kabiru CW, Beguy D, Crichton J, Zulu EM. HIV/AIDS among youth in urban informal (slum) settlements in Kenya: what are the correlates of and motivations for HIV testing? BMC Public Health 2011;11:685.

12. Babalola S. Readiness for HIV testing among young people in northern Nigeria: the roles of social norm and perceived stigma. AIDS Behav. 2007; 11(5):759-69.

13. Iyaniwura CA, Oloyede O. HIV testing among youths in a Nigerian local population. West Afr J Med. 2006; 25(1):27-31.

14. Berendes S, Rimal RN. Addressing the slow uptake of HIV testing in Malawi: the role of stigma, self-efficacy, and knowledge in the Malawi BRIDGE Project. J Assoc Nurses AIDS Care 2011; 22(3):215-28.

15. Hendriksen ES, Hlubinka D, Chariyalertsak S, et

I al. Keep talking about it: HIV/AIDS-related communication and prior HIV testing in Tanzania, Zimbabwe, South Africa, and Thailand. AIDS Behav. 2009;13(6):1213-21.

16. Matovu JKB, Makumbi FE. Expanding access to voluntary HIV counseling and testing in subSaharan Africa: alternative approaches for improving uptake, 2001-2007. Trop Med Int Health 2007; 12(11):1315-1322.

17. Guy RJ, Prybylski D, Fairley CK, Hellard ME, Kaldor JM. Can data from HIV voluntary counselling and testing be used to assess the impact of public health interventions? A literature review. Int J STD \& AIDS 2009,;20:378-83.

18. loveLife: Our strategy. Retrieved at http:// www.lovelife.org.za/about/strategy.php, accessed 10 October 2011. 
19. Statistics South Africa. Census 2001: Concepts and definitions. Pretoria: Statistics South Africa, 2004.

20. Snow RC, Madalane M, Poulsen M. Are men testing? Sex differentials in HIV testing in Mpumalanga Province, South Africa. AIDS Care 2010, 22(9):1060-1065.

21. Ziraba AK, Madise NJ, Kimani JK, Oti S, Mgmella G, Matilu M, Ezeh A. Determinants for HIV testing and counselling in Nairobi urban informal settlements. BMC Public Health 2011, 11:663.

22. Peltzer K, Matseke G, Mzolo T, Majaja M. Determinants of knowledge of HIV status in South Africa: results from a population-based HIV survey. BMC Public Health 2009, 9(174):1471-2458.
23. Palekar R, Pettifor A, Behets F, MacPhail C. Association between knowing someone who died of AIDS and behavior change among South African youth. AIDS Behav. 2008,12(6):903-12.

24. Mphaya JC, Roos JH, Ehlers VJ. Factors motivating young people in Malawi to go for voluntary counselling and testing for HIV. Afr J Nurs Midwifery 2008, 10:59-77.

25. MacPhail CL, Pettifor A, Coates T, Rees H. "You must do the test to know your status": attitudes to HIV voluntary counseling and testing for adolescents among South African youth and parents. Health Educ Behav. 2008, 35(1):87-104. 